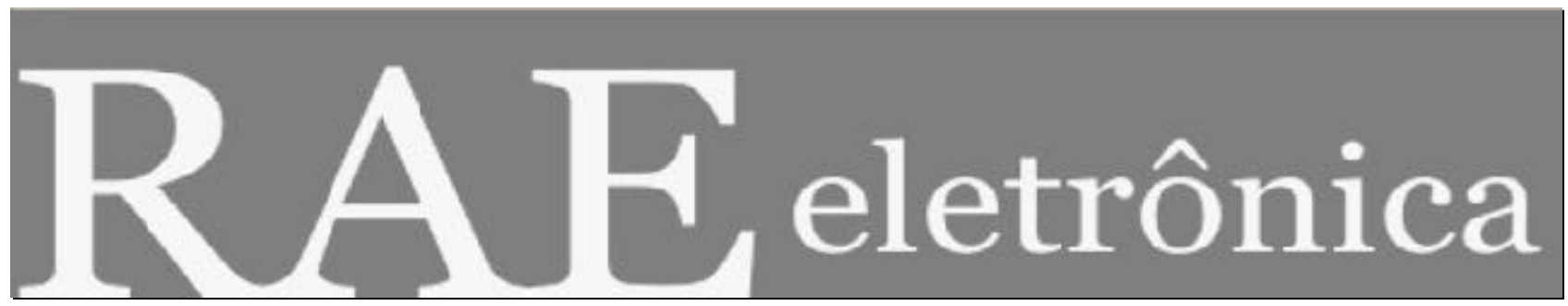

\title{
NEO-INSTITUCIONALISMO NA PRODUÇÃO ACADÊMICA EM ADMINISTRAÇÃO
}

Por:

\section{Charles Kirshbaum}

\section{Elvio Corrêa Porto}

\section{Fernando Coelho Martins Ferreira}

RAE-eletrônica, v. 3, n. 1, Art. 12, jan./jun. 2004

http://www.rae.com.br/eletronica/index.cfm?FuseAction=Artigo \&ID=2049\&Secao=ENSINO/PES\&V olume $=3 \&$ Numero $=1 \&$ Ano $=2004$

CCopyright, 2004, RAE-eletrônica. Todos os direitos, inclusive de tradução, são reservados. É permitido citar parte de artigos sem autorização prévia desde que seja identificada a fonte. A reprodução total de artigos é proibida. Os artigos só devem ser usados para uso pessoal e nãocomercial. Em caso de dúvidas, consulte a redação: redacao@ rae.com.br.

A RAE-eletrônica é a revista on-line da FGV-EAESP, totalmente aberta e criada com o objetivo de agilizar a veiculação de trabalhos inéditos. Lançada em janeiro de 2002, com perfil acadêmico, é dedicada a professores, pesquisadores e estudantes. Para mais informações consulte o site www.rae.com.br/eletronica.

RAE-eletrônica

ISSN 1676-5648

(C2004 Editora: Fundação Getulio Vargas - Escola de Administração de Empresas de São Paulo

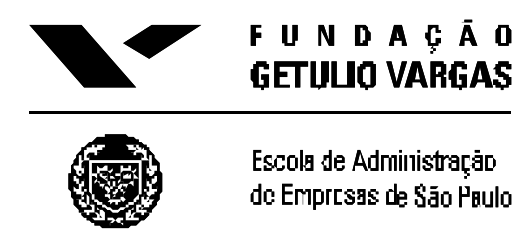




\title{
NEO-INSTITUCIONALISMO NA PRODUÇÃO ACADÊMICA EM ADMINISTRAÇÃOO
}

\begin{abstract}
RESUMO
O presente artigo investiga o processo de decisão de pesquisa das comunidades acadêmicas de Gestão no Brasil, especialmente frente às exigências da CAPES. Primeiramente, revisitamos a situação da academia brasileira antes das normas da CAPES, exploramos a seguir a reação dos acadêmicos frente ao novo marco institucional, fazendo uso de fontes secundárias e entrevistas com pesquisadores brasileiros e norte-americanos. Finalmente, traçamos algumas proposições preliminares para o processo decisório subjacente a esse comportamento. Concluímos com uma revisão de diversas formas adotadas pelas instituições brasileiras de tentativa de adaptação às normas e perspectivas futuras de evolução da pesquisa em Gestão no Brasil. Sugerimos que, ainda que a CAPES tenha desempenhado um papel fundamental de disciplinador do meio acadêmico, existe uma oportunidade de discussão do seu papel e arranjo institucional no longo-prazo, quanto às suas funções, na medida em que a academia não necessite mais de um órgão especializado para sustentar tanto o volume de pesquisa, quanto a sua interação com a comunidade.
\end{abstract}

\begin{abstract}
This article investigates the research decision-making process of Brazilian academic communities, focusing especially on the reaction to CAPES's requirements. Firstly, we revisit the Brazilian academy scenario before CAPES' new rules. Secondly, we explore the researchers' reaction upon the new institutional frame. Thirdly, we generate several propositions on the decision-process underneath such behavior, which are contrasted against the insights collected throughout interviews with Brazilian and American researchers. We expose the range of strategies the Brazilian institutions elaborated in order to cope with the new rules. In addition, we explore the interviewees' perspectives on the research in Brazil. Finally, we suggest that although CAPES has played a key-role in establishing a discipline to the academic field in Brazil, the academic community should raise the discussion on CAPES' role and institutional structure in long-term. The community should review CAPES' functions, in tandem with the higher maturity of the academy, and its interaction with the whole community.
\end{abstract}

\section{PALAVRAS-CHAVE}

CAPES, ensino em Administração, produção acadêmica, Administração, educação.

\section{KEY-WORDS}

CAPES, teaching in Management, academic research, Management, education. 


\section{INTRODUÇÃO}

A Academia em Administração no Brasil tem motivos para comemorar seu desempenho nos últimos anos: sua produção acadêmica aumentou, e o acadêmico tem se dedicado mais à pesquisa (BERTERO et al, 1999). Essa transformação ocorreu devido ao papel desempenhado pela CAPES, ao estabelecer o sistema de pontuação dos acadêmicos e exigir pontuação mínima para docentes pesquisadores.

No entanto, a institucionalização dos critérios de avaliação, ao privilegiar, por exemplo, algumas publicações sobre outras, pode enviesar o processo de seleção de objetos de estudo pelos pesquisadores: a autonomia de produção acadêmica permanece incólume frente aos critérios estabelecidos?

Esse artigo exploratório é contextualizado nas origens da produção acadêmica, no Brasil e no mundo e particularmente em Administração. Buscamos revisar a literatura disponível sobre o impacto das normas da Capes sobre a produção acadêmica no Brasil, assim como a percepção de alguns acadêmicos no Brasil sobre o ambiente atual de pesquisa. Comparamos os depoimentos dos acadêmicos brasileiros com algumas entrevistas com norte-americanos. Finalmente, sugerimos possíveis cenários para a evolução do papel da Capes.

\section{A PRODUÇÃO ACADÊMICA: DAS TREVAS ÀS LUZES?}

$\mathrm{Na}$ Idade Média, onde as primeiras academias começam a florescer na Europa, o acadêmico era uma figura bastante parecida com Guglielmo de "O Nome da Rosa", de Umberto Eco (1980). Essa figura recatada e submissa às autoridades eclesiásticas dará lugar ao pesquisador iluminista, que inspira a academia até os dias de hoje. Se até Carlos Magno o produtor de conhecimento encaixava-se a uma hierarquia piramidal (ver por exemplo RAIT, 1931), na modernidade o acadêmico insere-se em uma rede de relações horizontais da Universidade, que protege sua autonomia de investigação científica e promove sua vocação como guia para descobertas criativas que revolucionam o mundo.

Weber (1930), em seu clássico "Ética Protestante e Espírito do Capitalismo" aponta que a vocação que guia o homem moderno em seu trabalho tem, na verdade, uma origem religiosa protestante, como em um chamado: os modernos dedicam se ao trabalho como uma atividade de redenção de si mesmo e do mundo. Ao contrário do homem da Idade Média, que negava o mundo em busca de um paraíso superior, o homem moderno encontra sua salvação no seu trabalho, modificando o mundo. Em contraste com o homem medieval, sua salvação é individual.

Mas se essa mudança atingiu em cheio os reclusos homens medievais, o que se poderia dizer dos acadêmicos, especialmente aqueles em Gestão? Ainda estariam isolados em suas academias? Orientariam suas pesquisas em busca da solução metafísica do mundo ou buscariam pesquisas aplicadas? Estariam guiados por diretrizes institucionais ou pela própria curiosidade científica?

Se, em meados do século XIX, anos após as primeiras luzes de Bacon, Marx ainda se reclamava que "era hora de os filósofos pararem de entender o mundo para transformá-lo", poderíamos inferir que a aplicabilidade da produção acadêmica em seu entorno não era e não é banal, principalmente nas Ciências Sociais puras e aplicadas.

Clark e Palatella (1997) reportam que, até recentemente, as pesquisas produzidas em Economia nos Estados Unidos tinham pouca aplicação prática no planejamento econômico daquele país. Inversamente, aqueles acadêmicos que se aventuraram em trabalhar para o governo relatam que suas 


\section{ENSINO E PESQUISA EM ADMINISTRAÇÃO - NEO-INSTITUCIONALISMO NA PRODUÇÃO \\ ACADÊMICA EM A DMINISTRAÇÃO \\ Charles Kirschbaum - Élvio Corrêa Porto - Fernando Coelho Martins Ferreira}

teorias devem ser todas suspensas quando se voltam à prática. Mais recentemente, Jordan et al. (1999) relatam em uma pesquisa realizada entre leitores acadêmicos e praticantes (practitioners) de uma revista acadêmica de lazer americano a dificuldade que estes últimos possuíam em aplicar os resultados das pesquisas publicadas em sua realidade organizacional.

Já na Europa, mais especificamente no Reino Unido, observa-se uma reação ao isolamento da academia: a agenda governamental de financiamento de pesquisas britânicas, contando com a influência crescente de representantes do mercado no comitê governamental que toma a decisão sobre o destino das verbas, vem desde os anos oitenta privilegiando e encorajando pesquisas com "resultados comerciais", ou seja, com aplicação prática no ambiente das organizações e capazes de gerar dividendos às universidades. Além disso, o governo britânico também vem incentivando a participação das corporações no financiamento das pesquisas acadêmicas (EVANS, 2001). Entretanto, Evans (2001) alerta que este incentivo ao financiamento vindo do comércio e da indústria veio sem uma atenção concomitante à necessidade de se preservar uma distância (entre o financiamento e o controle da pesquisa) e enfatiza a ameaça que os interesses comerciais podem representar à autonomia das universidades britânicas, capazes de sacar destas a independênc ia e o desinteresse indispensáveis à busca da verdade e à credibilidade dos resultados das pesquisas. Essa ambivalência do atrelamento da pesquisa acadêmica a resultados externos à universidade denota a dificuldade de conciliação entre a autonomia acadêmica e as pressões do seu entorno.

Aqui no Brasil, observamos interessantes choques entre academia e "o-mundo-lá-fora", notoriamente na Economia e Política. Na Economia, o governo militar foi pesadamente criticado por adotar políticas dos Chicago Boys (graduados em Economia pela Universidade de Chicago), sem a devida adaptação à "realidade" local. Já na política, o ex-presidente Fernando Henrique Cardoso explicitamente refutou suas próprias teorias ao chegar ao governo. E finalmente, o presidente Luiz Inácio Lula da Silva, ao ser informado de sua vitória nas eleições presidenciais de 2002, afirmou que "ensinaria política para muitos cientistas políticos".

\section{A ACADEMIA DE GESTÃO NO MUNDO E NO BRASIL}

A situação da academia em Gestão, uma das ciências sociais aplicadas de maior expansão nos últimos anos, não difere em muito de suas primas Economia e Ciência Política. A própria existência de uma academia dedicada aos estudos de Gestão tem sido questionada por acadêmicos (ver por exemplo, PFEFFER e FONG, 2002), muitas vezes nos meios de divulgação que eles mesmos criaram.

De qualquer forma, em diversos centros de pesquisa, discussões recentes que envolvem o papel da pesquisa acadêmica em Gestão têm como ponto focal a sua relevância entendida pela proximidade e aplicabilidade dos seus enunciados à prática gerencial comum.

Reconhece-se, assim, a existência de um hiato entre a pesquisa em Gestão e os interesses das partes interessadas. Pfeffer e Fong (2002, p.86) apontam que é no mínimo questionável a validade da pesquisa acadêmica em Gestão, assim como a contribuição dos cursos de administração. "Embora acadêmicos sejam influenciados por praticantes [practitioners]", afirmam os autores, "pouca influência passa dos acadêmicos à indústria". A colocação dos autores questiona a própria legitimidade da existência de uma academia em Gestão e parece não reconhecer validade na construção de conhecimento destacado de aplicação pragmática e funcionalista. 


\section{ENSINO E PESQUISA EM ADMINISTRAÇÃO - NEO-INSTITUCIONALISMO NA PRODUÇÃO \\ ACADÊMICA EM A DMINISTRAÇÃO \\ Charles Kirschbaum - Élvio Corrêa Porto - Fernando Coelho Martins Ferreira}

Hambrick (1994, p.13) convoca seus pares da Academy of Management, principal associação de acadêmicos em Gestão dos Estados Unidos, à tomada de iniciativas concretas de aproximação ao mundo das empresas e à busca de maior internacionalização, quebrando, em certa medida, uma mentalidade restrita que sustenta um ciclo de produção da academia para si mesma, que ele próprio qualifica como "fechado e incestuoso".

Starkey e Madan (2001, p.5), em contrapartida, enxergam com bons olhos esse distanciamento, pois essa separação cria pressões em favor de mudanças na forma de produção da pesquis a acadêmica tradicional: (1) a postura crítica da comunidade "laica" demandando maior relevância por parte da academia; (2) a competitividade entre universidades levada em grande parte pela lucratividade dos cursos, em especial os de pós-graduação; (3) reflexão crítica dos próprios acadêmicos quanto ao seu papel social; e (4) desenvolvimentos acelerados recentes nas tecnologias de informação e comunicação. Esses fatores levam à reflexão sobre o papel da pesquisa acadêmica no processo de difusão e produção de conhecimento.

Entretanto, se por um lado os praticantes da administração creditam à relevância um significado instrumental para a solução de questões cotidianas e assim por eles consideradas prioritárias, a academia, por sua vez, não enxerga conteúdo nessa demanda ao relegá-la ao nível das instruções prescritivas que atendem a nada mais que o caráter fashion da administração.

A universidade entende que a sua função é compreender o processo gerencial e contribuir com idéias que possam aprimorá-lo como forma de pensamento e não como aplicação tecnológica. Indo além, Brown e Duguid (2000) citados por Starkey e Madan, (2001, p.7), afirmam que "a academia atinge sua efetividade máxima quando conduz pesquisas que o setor privado é incapaz ou indisposto a fazer." (tradução nossa)

Para Weick (2001), a relevância não é só devida a um alegado distanciamento da universidade ao mundo empresarial, mas também ao fato de que os executivos mostram-se mais motivados por modismos e gurus do que pela base essencial do conhecimento. Talvez a resolução desse antagonismo requeira reconhecimento de ambas as partes.

Mas se a questão da necessidade de relevância para os praticantes tem suscitado um debate intenso entre os acadêmicos, ainda mais acalorada tem sido a discussão de definir os critérios de relevância. Enquanto Leavitt (1996, p.12) mostra desapontamento em relação ao caráter narcisista que permeia a motivação dos pesquisadores atuais, Weick (2001, p.72) afirma que os pesquisadores acadêmicos insistem em temas já comuns ao meio empresarial e Porter e McKibbin (1988), citados por Starkey e Madan (2001), reconhecem que em muitos casos a "quantidade tornou-se mais importante que a qualidade", percebe-se uma interpretação difusa do que é ou não importante para o campo gerencial.

A mesma preocupação se observa nas instituições brasileiras. Entretanto, o questionamento local parece ter um foco um pouco diferente. A questão maior que se abate sobre a pesquisa feita no Brasil é atingir níveis de qualidade que permitam a aceitação em eventos fora do país e a publicação nas revistas acadêmicas internacionais de "primeira linha". O maior desafio que ainda se impõe aos pesquisadores brasileiros é o reconhecimento pela comunidade acadêmica internacional como padrão de qualidade. Conforme afirmam Bertero et al.(1999, p.150), o sistema de pós-graduação no Brasil carece de qualidade mundial, avaliado em termos do número de publicações em periódicos acadêmicos de nível internacional. 
É importante destacar que o referencial para reconhecimento tem sido estrangeiro. Este não é um fenômeno restrito ao Brasil, pois como observam Starkey e Madan (2001), a pesquisa de Gestão no Reino Unido também tem sido crescentemente influenciada pelos padrões e normas dos Estados Unidos, reforçando a observação de Koza e Thoenig (1995, p.1,2) de que as citações de autores americanos prevalecem nos estudos acadêmicos europeus em relação aos seus pares continentais, enquanto que as referências de estudos europeus nas publicações americanas são observadas com muito menor freqüência. Ainda que as diversidades idiomáticas podem servir como justificativa inicial e preliminar para este fenômeno, os autores acrescentam, no entanto, que a questão evolui também para própria definição do campo de atuação: enquanto a produção acadêmica européia é primariamente interessada em estudos qualitativos, gerados no seio de uma tradição humanista com propósitos de crítica social, o padrão americano se caracteriza mais pelo desenvolvimento e teste de teorias causais (p.2 e 3).

\section{A Pesquisa em Gestão Pós-Capes}

No Brasil, é alta a difusão de escolas de administração, não obstante, a produção acadêmica não alcançou ainda os padrões de outros programas nacionais. Segundo pesquisa recente realizada diretamente no site da CAPES (http://www.capes.gov.br), existem no Brasil 78 programas de pósgraduação stricto sensu indicados sob o título "administração", sendo 44 programas de mestrado, 14 de doutorado e 20 profissionais, oferecidos por 50 instituições de ensino superior espalhadas no território nacional. A distribuição dessas modalidades em termos da avaliação recebida pela CAPES encontra-se detalhada na tabela 1 . Observa-se claramente que mais de $60 \%$ dos programas de administração reconhecidos obteve conceito 3 , sendo 5 a maior nota alcançada por pouco menos de $13 \%$ dos programas, em uma escala cujo conceito máximo correspondente a 7 . Dentro da classificação de ciências sociais aplicadas, os programas de administração são em maior número, seguidos pelas áreas de economia e direito, com 64 e 56 programas, respectivamente.

\section{Tabela 1 - Distribuição dos conceitos da pós -graduação em Administração no Brasil.}

\begin{tabular}{|l|r|r|r|r|}
\hline & Mestrado & Doutorado & Profissional & Total \\
\hline Conceito 3 & 31 & 1 & 15 & 47 \\
\hline Conceito 4 & 8 & 10 & 3 & 21 \\
\hline Conceito 5 & 5 & 3 & 2 & 10 \\
\hline Total de programas & 44 & 14 & 20 & 78 \\
\hline Total de instituições & 50 & & & \\
\hline
\end{tabular}

Ao contrário dos Estados Unidos e também da Europa Ocidental, a grande massa de professores de administração no Brasil se dedicou prioritariamente ao ensino e consultoria, em detrimento da pesquisa acadêmica. Ironicamente, portanto, nunca se pode acusar o acadêmico de Gestão no Brasil de estar fora do mundo, pois a maior parte de suas atividades dizia respeito a questões extremamente mundanas: a aplicação de ferramental em problemas oferecidos por clientes e a formação da classe gerencial no país.

Nos últimos anos, como decorrência direta das diretrizes da CAPES, houve um grande salto na produção acadêmica em administração no país, medido em termos de quantidade, entretanto aparentemente não se constatou que os níveis de qualidade dessa produção tenham apresentado a mesma tendência (BERTERO et al., 1999). É válido de nota, entretanto, que mesmo em termos de 


\section{ENSINO E PESQUISA EM ADMINISTRAÇÃO - NEO-INSTITUCIONALISMO NA PRODUÇÃO \\ ACADÊMICA EM A DMINISTRAÇÃO \\ Charles Kirschbaum - Élvio Corrêa Porto - Fernando Coelho Martins Ferreira}

quantidade, a produção média por pesquisador está aquém dos níveis internacionais (CÂMARA LEAL, 2003).

Além disso, observa-se que a pesquisa sofre de grande distanciamento da comunidade em que a academia está inserida. A produção brasileira, segundo levantamento realizado por Bertero e Keinert (1994), citados por Bertero et al. (1999), é de inclinação predominantemente voltada ao público acadêmico, o que indica pouca preocupação com a aplicabilidade e pouca atenção ao universo gerencialista e à problemática concreta enfrentada por executivos. Os autores argumentam que a produção nacional seria, portanto, um fenômeno da academia, nela gerada e por ela própria consumida, confirmando o mesmo sentimento percebido por acadêmicos de centros mais tradicionais.

As temáticas são geralmente alinhadas com as discussões internacionais, no entanto se limitam a comprovar a teoria na realidade nacio nal (ARKADER, 2003; TONELLI et al, 2003). Pouco ou nenhum esforço tem sido feito em contribuir proativamente à construção de teoria no cenário mundial (ARKADER, 2003), utilizando-se das mesmas metodologias científicas consagradas e aprovadas pelas revistas acadêmicas de primeira linha.

Finalmente, ainda há baixa retenção do acadêmico na Academia em seu papel primordial de gerador de conhecimento por meio de pesquisa (DAVID VIEIRA, 2003). Infelizmente os incentivos não ajudam: a remuneração ao professor-pesquisador com dedicação integral é geralmente muito inferior à renda que um professor com dedicação parcial obtém, complementando suas aulas com a atividade de consultoria.

Podemos então, frente a esse quadro, construir um "sistema" de produção acadêmica (Figura 1), e o sumário das falhas ao longo de suas etapas (Quadro 1):

Figura 1 - Sistema de produção acadêmica.

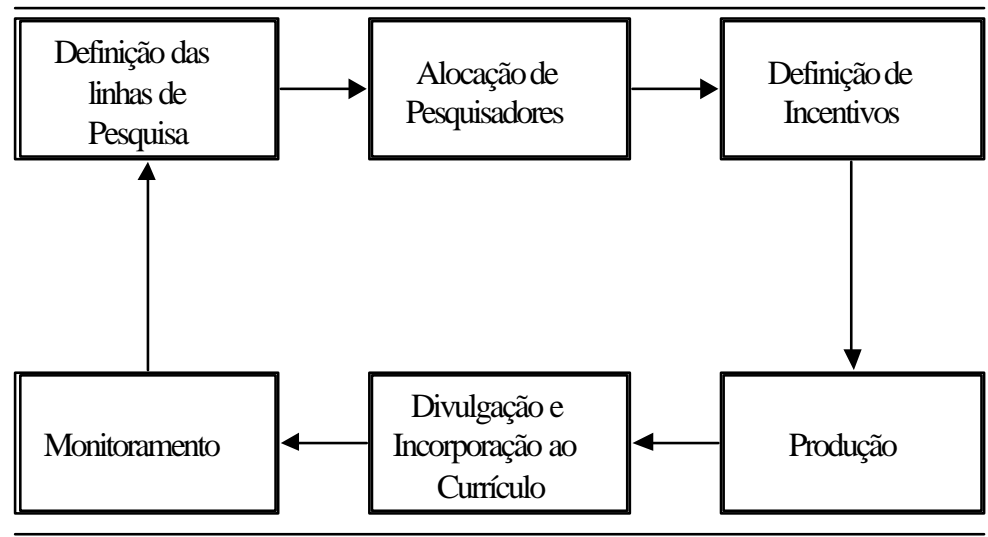




\section{Quadro 1 - Sumário de falhas no sistema de produção acadêmica.}

\begin{tabular}{l|l}
\hline \multicolumn{1}{c|}{ Etapa } & \multicolumn{1}{c}{ Falhas } \\
\hline Definição das linhas de pesquisa & $\bullet$ Distante da realidade nacional \\
& $\bullet \quad$ Reprodução de teorias internacionais \\
\hline Alocação de Pesquisadores & $\begin{array}{l}\bullet \text { Apenas recentemente vinculada à } \\
\text { produtividade }\end{array}$ \\
\hline Definição de Incentivos & $\begin{array}{l}\bullet \text { Falta de remuneração suficiente para } \\
\text { pesquisadores de tempo integral }\end{array}$ \\
\hline Produção & $\bullet \quad$ Uso escasso de material empírico \\
\hline Divulgação e Incorporação ao Currículo & $\bullet \quad$ Uso de casos que se "ajustam" à teoria \\
\hline Monitoramento & $\bullet \quad$ Baixa integração ao currículo de disciplinas \\
& $\begin{array}{l}\bullet \quad \text { Reaca divulgação para fora do meio acadêmico } \\
\text { consolidação }\end{array}$ \\
\hline
\end{tabular}

\section{OS ACADÊMICOS EM ADMINISTRAÇÃO SE PRONUNCIAM - METODOLOGIA DE PESQUISA}

O acadêmico em administração no Brasil está em uma encruzilhada: por um lado, já não pode mais legitimar sua posição apenas com a atividade docente, sendo obrigado a produzir conhecimento. Por outro lado, sua pesquisa não atende os critérios de excelência esperados. Cabe o questionamento, portanto, de como os departamentos de administração vêm lidando com as pressões da CAPES, por um lado, e as escolhas pessoais dos acadêmicos, por outro. Nesse jogo de forças, toma-se em conta a opinião da comunidade ou esta continua sendo passiva na formação de conhecimento? Finalmente, se os desafios enfrentados pelo acadêmico brasileiro não são tão diferentes dos desafios dos pesquisadores de outros países, é possível aprender algo com a experiência externa?

Nesse estudo exploratório, buscamos agregar às fontes secundárias entrevistas com acadêmicos em Gestão, intimamente ligados à pesquisa em suas áreas (ver Quadro 2 para o roteiro das entrevistas). Visamos justamente capturar a reflexão desse acadêmico no umbral entre dois mundos. 


\section{Quadro 2 - Roteiro de entrevista.}

\begin{tabular}{|c|c|}
\hline Tema & Questões \\
\hline $\begin{array}{l}\text { I. Descrição das Linhas de Pesquisa do } \\
\text { Departamento }\end{array}$ & $\begin{array}{l}\text { 1. Quais são as linhas de pesquisa existentes no seu } \\
\text { departamento? } \\
\text { 2. Desde quando existem essas linhas de pesquisa? }\end{array}$ \\
\hline $\begin{array}{l}\text { II. Processo de Decisão por linhas de } \\
\text { Pesquisa }\end{array}$ & $\begin{array}{l}\text { 3. Qual é a formalidade envolvida nesse processo de definição? } \\
\text { 4. O que é levado em conta na escolha de linhas de pesquisa? } \\
\text { 5.Como se procede a atualização das linhas de pesquisa? } \\
\text { 6.Como é a comunicação entre os departamentos para a } \\
\text { definição de linhas de pesquisa? } \\
\text { 7.Como são tratados "modismos"? }\end{array}$ \\
\hline $\begin{array}{l}\text { III. Operacionalização das Linhas de } \\
\text { Pesquisa }\end{array}$ & $\begin{array}{l}\text { 8.Quais são os critérios para a inclusão de um professor em } \\
\text { uma ou mais linhas de pesquisa? } \\
\text { 9.Quais são as estratégias de retenção do professor na } \\
\text { academia para gerar produção acadêmica? } \\
\text { 10.Em que medida alunos de mestrado/doutorado podem } \\
\text { definir seus campos de trabalho? } \\
\text { 11.Como é feito o balance amento entre "oferta" de } \\
\text { orientadores em determinada linha versus "procura" de } \\
\text { orientação pelos alunos? } \\
\text { 12.Que tipo de direcionamento/aconselhamento é oferecido } \\
\text { para os alunos para "encaixá-los" nas linhas de pesquisa } \\
\text { existentes? } \\
\text { 13.Você considera a verba destinada às pesquisas no seu } \\
\text { departamento suficiente? }\end{array}$ \\
\hline $\begin{array}{l}\text { IV. Monitoramento da produção } \\
\text { acadêmica }\end{array}$ & $\begin{array}{l}\text { 14.Qual é o acompanhamento que se procede quanto à } \\
\text { produção de cada linha? Como é averiguada a qualidade? } \\
\text { 15.Qual é o principal cliente da produção acadêmica do seu } \\
\text { departamento? } \\
\text { 16. Você considera que tudo que é atualmente produzido nas } \\
\text { linhas de pesquisa de seu departamento possui aplicabilidade } \\
\text { na administração de empresas no Brasil? }\end{array}$ \\
\hline $\begin{array}{l}\text { V. Avaliação do Modelo de "Linhas } \\
\text { de Pesquisa" }\end{array}$ & $\begin{array}{l}\text { 17.A divisão do departamento em linhas funciona? } \\
\text { 18.Como é percebida a evolução das linhas de pesquisa? Como } \\
\text { foi nos últimos } 10 \text { anos? Como se espera que seja nos } \\
\text { próximos } 10 \text { anos? }\end{array}$ \\
\hline
\end{tabular}

Entrevistamos quatro chefes de departamento de instituições brasileiras, sendo três da EAESP-FGV (identificados como entrevistados 1, 2 e 3) e um da FEA-USP (entrevistado 4). Em contrapartida, enviamos o mesmo questionário para alguns acadêmicos americanos (entrevistados 5 e 6), para que suas respostas servissem de contraste aos resultados que obtivemos nas entrevistas brasileir as. Desta forma, obteríamos uma idéia melhor do que seria específico de nosso país e aquilo comum a todos os departamentos de administração nos seus desafios de produção. 


\section{Resultados da Pesquisa e Proposições}

Em nossas entrevistas, existiu um sentimento predominante de preocupação com a comunidade, tanto entre os pesquisadores brasileiros, quanto entre os pesquisadores americanos. Entretanto, essa interação se dá de formas muito distintas. O acadêmico brasileiro divide-se em duas categorias: aquele que leciona e participa em consultoria, e aquele "puro pesquisador". O primeiro grupo, mais tradicional, estaria mais ligado à realidade empresarial ao implementar o ferramental teórico para resolver problemas práticos. Ao material produzido, chamamos de "pesquisa aplicada". Esse é o caso, por exemplo, da atividade do Centro de Estudos em Finanças (CEF), no Departamento de Finanças e Controladoria na EAESP, e da consultoria da Fundação Instituto de Administração (FIA), na Faculdade de Economia e Administração (FEA). Nossos entrevistados manifestaram seu descontentamento em relação à CAPES por não reconhecer a "pesquisa aplicada" como produção acadêmica para fins de avaliação. O entrevistado 4 chega a sugerir uma revisão dos critérios da CAPES para que possa abarcar a realidade da pesquisa em administração.

Uma outra forma de conferir proximidade da produção acadêmica ao ambiente empresarial se faz pelo incentivo explícito à produção de artigos e pesquisas, mesmo por alunos de pós-graduação stricto sensu, com algum tipo de contribuição envolvendo a pesquisa em campo, evitando-se assim trabalhos eminentemente teóricos e desconexos à realidade (entrevistado 2).

O segundo grupo de pesquisadores, aqueles que estão bastante inseridos no debate teórico internacional, corre o risco de distanciar-se da realidade de negócios do país. O entrevistado 3 menciona que, embora a colocação da EAESP como centro de excelência em Economia Financeira no mundo, não se deveria perder de vista a pesquisa mais tradicional ligada às Finanças Corporativas, crucial à comunidade de negócios no Brasil. Já o entrevistado 4 está satisfeito com o balanço alcançado pela FEA: "se a CAPES nos obriga a publicar internacionalmente, mantemos o contato com a realidade brasileira por meio de estudos de caso comparados".

Já nas entrevistas com os acadêmicos americanos, percebemos uma ligação mais "orgânica" entre comunidade e academia. O Entrevistado 5 descreve que $60 \%$ a $70 \%$ de sua pesquisa é aplicada e é guiada sobretudo para desembocar em disciplinas para a pós-graduação. O papel do patrocinador (sponsor), enquanto provedor privado de fundos e "cliente" da pesquisa, surge como elo de reforço entre a academia e a comunidade. No Brasil, embora a prática de consultoria emule o papel do patrocinador americano, esta apresenta elementos distintos que impactam na criação de conhecimento. Os projetos de consultoria são mais rápidos e geralmente exigem apenas a aplicação da teoria já instrumentalizada, principalmente devido a maior pressão por evidências positivas e imediatas nos resultados da empresa cliente. Dessa forma, sugerimos nossa primeira proposição:

Proposição 1: Em geral, o acadêmico no Brasil segue tendências mundiais e seus próprios interesses de pesquisa. Não há uma "estratégia" que ordene a pesquisa sob o ponto de vista da instituição em que está filiado. Da mesma forma, há baixa participação pró-ativa da comunidade em definir as temáticas de pesquisa, em comparação com a participação da comunidade nos Estados Unidos.

Os entrevistados 5 e 6 são explícitos sobre a autonomia do pesquisador nos Estados Unidos: esse é um valor intocável. Para ambos pesquisadores, o acadêmico americano, ou "qualquer um que coloque o título de $P h D$ junto ao seu nome" (entrevistado 6), não se sujeitará a definições "de cima para baixo" do que deve ser pesquisado. Esse é o elemento de liberdade acadêmica que sugerimos, no início do artigo, que surge no Iluminismo. 
Os valores de liberdade acadêmica são compartilhados também aqui por pesquisadores brasileiros, no entanto existe de forma mais tímida ou mais incisiva a idéia de ordenamento dessa liberdade sob a "estratégia" da instituição. O entrevistado 4, por exemplo, defende a liberdade acadêmica como um valor inalienável de pesquisadores em uma instituição pública. No entanto, reconhece as vantagens que uma estratégia conjunta poderia ter no desenvolvimento de pesquisa. Essa percepção fica ainda mais evidente no depoimento do entrevistado 3, onde a EAESP deveria desenvolver linhas de pesquisas não em função da disponibilidade de pesquisadores que atendam aos pré-requisitos da CAPES, mas em função de sua "Missão". Da mesma forma, o departamento de Finanças deveria ter um bom balanço entre os diversos campos de conhecimento e resistir à tentação de especializar-se em apenas um campo de investigação (atualmente, Economia Financeira é o campo de excelência do departamento de Finanças da EAESP).

O que não fica evidente é a conexão do interesse individual do pesquisador a um propósito mais abrangente definido no âmbito da instituição de que faz parte. Respeitando-se a liberdade acadêmica como valor inalienável, não há evidência de que as definições das linhas e objetos de pesquisa se enquadram nas diretrizes institucionais. A evidência observada, em contraste, foi a ausência de "estratégias" e "missões" formalizadas:

Proposição 2: O pesquisador brasileiro reteve sua autonomia de escolha de pesquisa em relação às instituições de ensino. Ainda que haja pressões para um planejamento de temáticas a serem investigadas, a decisão de tema de pesquisa é tomada pelo pesquisador.

O fenômeno do isomorfismo na produção acadêmica ocorre tanto entre os acadêmicos americanos quanto europeus. Segundo DiMaggio e Powell (1991) , fundadores da escola de "neoinstitucionalismo", as organizações tendem a adotar um comportamento isomórfico, ou seja, tendem a assemelhar-se com o tempo. Esse comportamento tem três fontes: coercitivo (leis e regras impostas), mimético (imitação) e normativo (condutas e práticas comuns aos profissionais do ramo de atividade).O isomorfismo é inerente a qualquer atividade humana, e também na academia. $\mathrm{O}$ sistema americano, como o referencial estrangeiro a que tivemos acesso durante nossa pesquisa, é fortemente baseado nos patrocinadores e nos blind reviewers. Se o primeiro dita a quantidade de artigos a serem publicados, o segundo define as temáticas a serem aceitas nas principais revistas acadêmicas e o nível de qualidade necessário para sua aceitação. Assim, a "liberdade acadêmica" é condicionada por agentes externos à instituição. No entanto, essa situação é amenizada na medida em que os patrocinadores vêm sendo mais envolvidos com o conteúdo da produção acadêmica, ao mesmo tempo em que os blind reviewers são, nada mais, nada menos, que os próprios acadêmicos em estágio maduro da carreira. $\mathrm{O}$ lastro de qualidade, portanto, está na tradição de pesquisa. Esse lastro garante uma continuidade no desenvolvimento científico, mas também confere inércia para os atuais campos de investigação.

No Brasil, o isomorfismo se dá de forma bastante distinta do fenômeno observado nos Estados Unidos. Se naquele país o isomorfismo teria, digamos, sua maior fonte a partir do mimetismo e de práticas profissionais consolidadas - pois os acadêmicos imitam-se mutuamente e são formados pelas mesmas instituições - no Brasil, a maior fonte de isomorfismo é coercitivo (entrevistado 1). A CAPES exige que os acadêmicos de tempo integral atendam metas de produção e publiquem em revistas acadêmicas selecionadas. O resultado dessa imposição é que muitas vezes a vida pessoal de professores e alunos é prejudicada, a variedade dos trabalhos torna-se escassa e a qualidade do que é produzido não é garantidamente boa. O professor é pressionado a produzir mesmo quando não está maduro para fazê-lo. O entrevistado 3 aponta como a avaliação da EAESP em Finanças foi prejudicada sobretudo porque os periódicos que os pesquisadores da instituição costumam publicar não haviam sido homologados pela 


\section{ENSINO E PESQUISA EM ADMINISTRAÇÃO - NEO-INSTITUCIONALISMO NA PRODUÇÃO \\ ACADÊMICA EM A DMINISTRAÇÃO \\ Charles Kirschbaum - Élvio Corrêa Porto - Fernando Coelho Martins Ferreira}

CAPES. Em contraste, por não existir uma tradição de pesquisa forte como em países desenvolvidos, o isomorfismo mimético e normativo ainda é incipiente: os campos ainda têm em seus quadros de professores de pós-graduação acadêmicos que não vieram da tradição acadêmica, mas da tradição de consultoria. Portanto, cabe ainda questionar se a formação de acadêmicos pesquisadores no país pode se dar a partir de orientadores que não sejam pesquisadores eles próprios.

Uma vertente mimética é identificada na forma como se geram inspirações e interesses para a realização de pesquisas, que normalmente seguem orientações colhidas na participação de congressos e eventos internacionais (entrevistado 2). Ou seja, não se identificou evidência de que a academia em Gestão no Brasil tenha até o presente momento, criado algum campo de pesquisa que seja de interesse eminentemente nacional:

Proposição 3: O processo de decisão e produção acadêmica no Brasil segue um comportamento isomórfico, com forte vertente coercitiva. Os acadêmicos orientam sua produção acadêmica majoritariamente para o cumprimento das metas estipuladas pela CAPES.

Entre os entrevistados brasileiros, ainda que reclamem sobre a interferência da CAPES sobre sua atividade, o saldo é positivo sobre seu impacto ao longo prazo na produção acadêmica no Brasil. O entrevistado 3, por exemplo, confessa ter "despertado" para a possibilidade de colocação de Finanças na EAESP como um dos melhores departamentos dessa área no mundo. O entrevistado 4, da FEA, enxerga no aumento de volume de produção e no maior rigor dos blind reviewers uma tendência irreversível de aumento de qualidade na produção brasileira.

Para os acadêmicos americanos, as perspectivas são bem mais modestas, dada a maturidade alcançada pela academia. $\mathrm{O}$ entrevistado 5 espera que algumas linhas de pesquisa sejam abandonadas e outras, incorporadas, mas não existirão grandes mudanças estruturais na academia americana:

Proposição 4: Os acadêmicos brasileiros esperam a manutenção do crescimento da produção brasileira nos próximos, em paralelo com um aumento de qualidade.

As proposições acima podem ser exploradas com maior profundidade por estudos futuros, aumentandose a amostra de entrevistados e utilizando-se de questionários estruturados. No entanto, o contexto obtido de fontes primárias e secundárias nos permite traçar algumas conjecturas sobre o futuro do ambiente institucional de pesquisa no Brasil.

\section{CONCLUSÃO}

Em contraste com o aumento na quantidade de trabalhos referenciados em Gestão, produzidos no âmbito da academia brasileira como resultado às pressões crescentes da CAPES, ainda falta discutir a questão de carência de qualidade na produção acadêmica nacional. A qualidade dos trabalhos se mantém insatisfatória para atender os requisitos oficiais. Se o rebaixamento de instituições (que até então se sustentavam pela tradição e renome na comunidade) gerou um "estímulo" para o ajustamento aos critérios estabelecidos, ao mesmo tempo suscitou o debate da legitimidade desses critérios.

As entrevistas sugerem que as universidades brasileiras ainda estão em fase de adaptação ao que delas agora é exigido. Os direcio namentos impostos pela CAPES lhes são divergentes da tradição com que vinham até o momento prestando retribuição à comunidade. Isso implica em mudanças não apenas no conteúdo do trabalho desenvolvido, como também no perfil do próprio acadêmico e nas perspectivas de 
carreira oferecidas por um novo cenário em que a consultoria, em posição desfavorecida, concorre com a dedicação implícita ao desenvolvimento de pesquisa.

Ainda que os critérios adotados pela CAPES sejam próximos aos internacionalmente consagrados (ao promover o lema "publicar ou perecer"), eles são, como visto, controversos. A CAPES foi levada a estabelecer critérios explícitos de avaliação da produção final dos pesquisadores, ao tentar reverter uma inércia que privilegiava o modelo de acadêmico-consultor. Entretanto, esses critérios atrelam a pesquisa a periódicos e que não necessariamente oferecem uma contribuição de desenvolvimento da comunidade.

Paradoxalmente, a exigência de retenção do acadêmico na produção de pesquisa pode levar a um afastamento do meio empresarial em que estava até então inserido, muitas vezes como consultor. Ao atender os critérios de internacionalização de sua pesquisa, o acadêmico pode ser levado a produzir informação irrelevante para a sociedade civil brasileira.

Acreditamos que a comunidade acadêmica enfrentará nos próximos anos um debate sobre o papel da CAPES e suas funções. Essa discussão, ao nosso ver, pode se dar na revisão de três alternativas de sistema de produção acadêmica. Cada uma dessas alternativas, por nós idealizadas, apresenta combinações diversas entre quantidade, qualidade, relevância e liberdade acadêmica:

\section{Alternativa 1: Manutenção do funcionamento atual}

O modelo atual é responsável pelo aumento da produção acadêmica, maior retenção do acadêmico na instituição (com a gradual mudança dos incentivos em decorrência da pressão por boas avaliações) e sensibilização sobre a importância de criação de teoria. Entretanto, sua manutenção cristaliza algumas tendências que podem restringir a liberdade acadêmica: a escolha das revistas acadêmicas e publicações, sua classificação e homologação é, de certa forma, uma definição indireta dos temas que devem ser abordados pelos acadêmicos. Atualmente, por exemplo, o reconhecimento de revistas acadêmicas internacionais como de primeira linha tem provavelmente incentivado os pesquisadores brasileiros a eleger temáticas de menor relevância para a comunidade de negócios local (ainda que a tentativa de conciliação seja permanentemente perseguida, como observamos, por exemplo, m FEA). As comunidades acadêmicas têm conseguido sugerir à CAPES quais deveriam ser as publicações requeridas para sua avaliação, entretanto esse processo ainda requer uma mediação e deliberação de um órgão supra-acadêmico.

\section{Alternativa 2: Maior Democratização da CAPES}

A maior democratização da CAPES mitigaria os problemas apontados no funcionamento atual. Idealmente, um órgão deliberativo que fosse suficientemente sensível às múltiplas necessidades dos diferentes campos poderia ajustar os critérios de avaliação a uma "vontade geral" dos acadêmicos. Entretanto, como Aristóteles bem o sabia, toda democracia pode degenerar em demagogia. Com critérios mais brandos ou ajustados para aceitar as particularidades de todos acadêmicos, corre-se o risco de perder compktamente o critério de qualidade. Portanto, mesmo se concebermos um modelo mais democrático, sempre haverá um elemento de arbitrariedade nas diretrizes desse órgão.

Alternativa 3: Transferência das Atribuições da CAPES para a Sociedade Civil

Espelhando-se nos modelos dos países anglo-saxões, o papel coercitivo da CAPES seria diluído e internalizado pelas próprias instituições acadêmicas (como relatado por nosso entrevistado 5). A 


\section{ENSINO E PESQUISA EM ADMINISTRAÇÃO - NEO-INSTITUCIONALISMO NA PRODUÇÃO \\ ACADÊMICA EM A DMINISTRAÇÃO \\ Charles Kirschbaum - Élvio Corrêa Porto - Fernando Coelho Martins Ferreira}

CAPES deixaria de exercer o papel de "policial" do meio acadêmico, para tornar-se um órgão apenas consultivo. A definição de metas passaria às próprias instituições, em resposta às demandas da sociedade (como apontado pelo entrevistado 1 como a característica marcante da produção acadêmica em países anglo-saxões); talvez até com a emergência do papel do patrocinador. Ainda que esta alternativa seja charmosa, por replicar o sucesso de autonomia acadêmica dos países desenvolvidos, contrapõem-se duas objeções óbvias: (1) é um modelo importado e (2) é utópico para a situação em que se encontra a academia atualmente. Além disso, teríamos que enfrentar o isomorfismo mimético que é inerente a esta alternativa. $\mathrm{O}$ desafio de manter a produção acadêmica no mundo e evitar o solipsismo será o mesmo daquele enfrentado por nossos colegas americanos.

As três alternativas sugeridas acima não têm a pretensão de oferecer uma "solução" para o debate atual sobre o papel da CAPES e o rumo da produção acadêmica no país. Sugerimos uma outra tonalidade: "tipos ideais" (para usar novamente o palavreado weberiano) que podem ser aventados no momento propositivo desse debate, cuja problemática subjacente é ainda a vocação e autonomia acadêmica frente ao Leviatã institucional de salvaguardas.

\section{Artigo recebido em 01.08.2003. Aprovado em 06.01.2004.}

\section{REFERÊNCIAS BIBLIOGRÁFICAS}

ARKADER, R. A pesquisa científica em gerência de operações no Brasil. Revista de Administração de Empresas - RAE, São Paulo: FGV, v. 43, n. 1, p. 70-80, 2003.

BERTERO, C. O.; CALDAS, M. P.; WOOD Jr., T. Produção científica em administração de empresas: provocações, insinuações e contribuições para um debate local. Revista de Administração Contemporânea - RAC, Curitiba: CEPPAD/UFPR, v. 3, n. 1, p. 147-178, 1999

BROWN, J. S.; DUGUID, P. The Social Life of Information. Harvard Business Review School Press, Boston, 2000 apud STARKEY, Ken; MADAN, Paula. Bridging the relevance gap: aligning stakeholders in the future of Management research. British Journal of Management, v.12, special issue, p.3-26, 2001.

CÂMARA LEAL, R.P. et al. Perfil da pesquisa em fnanças no Brasil. Revista de Administração de Empresas - RAE, São Paulo: FGV, v. 43, n. 1, p. 91-104, 2003.

CLARK, R. E.; PALATELLA, J. (Org). The real guide to grad school New York: Lingua Franca, 1997. 511p.

DAVID VIEIRA, F.G. "Narciso sem espelho: a publicação brasileira de marketing". Revista de Administração de Empresas - RAE, São Paulo: FGV, v. 43, n. 1, p. 81-90, 2003.

DIMAGGIO, P. J.; POWELL, W. W. The iron cage revisited: institutional isomorphism and collective rationality in organizational fields. In: The nw institutionalism on organizational analysis.

Londres: The University of Chicago Press, 1991. Cap. 3, p. 69-70.

ECO, U. Il nome della rosa. Milano: Bompiani, 1980. 442p.

EVANS, G. R. The Integrity of UK Academic research under commercial threat. Science as Culture, v. 10, n. 1, p. 97-111, 2001. 


\section{ENSINO E PESQUISA EM ADMINISTRAÇÃO - NEO-INSTITUCIONALISMO NA PRODUÇÃO \\ ACADÊMICA EM A DMINISTRAÇÃO \\ Charles Kirschbaum - Élvio Corrêa Porto - Fernando Coelho Martins Ferreira}

HAMBRICK, D. C. What if the academy actually mattered? Academy of Management Review, v. 19, n. 19, p. 11-16, 1994.

JORDAN, D. J.; ROLAND, M. An examination between academics and practitioners in frequency of reading research and attitudes toward research. Journal of Leisure Research, v. 31, n. 2, p. 166-170, 1999.

KOZA, M. THOENIG, J. Organizational theory at the crossroads: some reflections on european and united states approaches to organizational research. Organization Science, v. 6, n. 1, p. 1-8, jan/fev.1995.

LEAVITT, H. J. The old days, hot groups and managers' lib. Administrative Science Quarterly, v. 41, n. 2, p. 288-300, 1996.

PFEFFER, J.; FONG, C. T. The end of business schools? Less success than meets the eye. Academy of Management and Education, v. 1, n. 1, p. 78-95, 2002.

RAIT, R. S. (1931). Life in the medieval university. Cambridge: Cambridge University Press. Disponível em: http://www.questia.com/PM.qst?action=openPageViewer\&docId=9409648, acessado em: 22/10/03.

STARKEY, K; MADAN, P. Bridging the relevance gap: aligning stakeholders in the future of Management research. British Journal of Management, v. 12, special issue, p.3-26, 2001.

TONELLI, M.J. et al. Produção acadêmica em recursos humanos no Brasil: 1991-2000". Revista de Administração de Empresas, v. 43, n. 1, p. 105-122, 2003.

WEBER, M. The protestant ethic and the spirit of capitalism. London: HarperCollins, 1930. 292p.

WEICK, K. E., Gapping the relevance bridge: fashion meet fundamentals in management research. British Journal of Management, v. 12, special issue, p. 71-75, 2001.

\section{Charles Kirschbaum}

Doutorando em Administração de Empresas pela FGV-EAESP. MBA pela Wharton School University of Pennsylvania. Bacharel em Administração de Empresas pela FGV-EAESP.

E-mail: kircharles@gvmail.br

Endereço: Rua Professor Alexandre Correia, no 291 - ap. 41, Morumbi, São Paulo - SP, 05657-230.

Interesses de Pesquisa: Estratégia, redes sociais, neo-institucionalismo, identidade social, indústria cultural.

\section{Elvio Corrêa Porto}

Mestrando em Administração de Empresas pela FGV-EAESP. Bacharel em Administração de empresas pela FGV-EAESP.

E-mail: eporto@gvmail.br

Endereço: Rua Canário, 988 - ap.93, Indianópolis, São Paulo - SP, 04521-004.

Interesses de Pesquisa: Cadeia de suprimentos, micro, pequenos e médios negócios, clusters e distritos industriais, neo-institucionalismo organizacional. 


\section{Fernando Coelho Martins Ferreira}

Mestrando em Administração de Empresas pela FGV-EAESP. Bacharel em Administração de Empresas pela FEA-UFJF.

E-mail: fferreira@gvmail.br

Endereço: Rua Prof. Picarolo, no 163 - E, apto. 132, Bairro Bela Vista, São Paulo - SP, 01332-020.

Interesses de Pesquisa: Clusters industriais, Resource-Based View, cadeia de suprimentos, Efficient Consumer Response, isomorfismo. 